ORIENTAL JOURNAL OF
ISSN: 0974-6471
March 2017,
COMPUTER SCIENCE \& TECHNOLOGY

\title{
Evaluation of Object Utilization Through Statistical Model in Software Development Process
}

\author{
KUMAR RAHUL ${ }^{1 *}$, BRIJESH KUMAR SINHA ${ }^{1}$ and VIJAY KUMAR ${ }^{2}$ \\ 'Department of Computer Science \& System Studies Mewar University, India. \\ ${ }^{2}$ Department of Basic and Applied Science NIFTEM, India. \\ ${ }^{*}$ Corresponding author Email: rahulmese @ gmail.com \\ http://dx.doi.org/10.13005/ojcst/10.01.22
}

(Received: March 06, 2017; Accepted: March 16, 2017)

\begin{abstract}
Objects needs verification through statistical model in software development process which are important in software industries now a day. Software development process consist of several steps right from analysis to deployment and maintenance, therefore statistical model would certainly analyses object(s) and its various qualities and its relationship during software development process. Earlier, we have designed a TMS where, object(s) being available for various purposes like accessibility, reusability in a development of software product or embedded product, thus statistical model justify the level of accessibility in terms of profitability and quantity of access. So far various statistical models have been implemented to identify and established the relationship but not all statistical model are used to analyses and calculate the parametric standard and determine the reusability factor in software development process model. In fact, this statistical model justified at various level of development and would help in determine cost of accessibility (CoA) and cost of reusability $(\mathrm{CoR})$
\end{abstract}

Keywords: Transaction Management System(TMS), Statistical Model, Software Qualties.

\section{INTRODUCTION}

Statistical method test is an important step in developing and maintaining any application software and embedded software before implementation. Although, different statistical method is used to enhance the performance through the past decades. Moreover, the final objective of statistical method has been remained standard over the years. In any software system implementation, objects determine the size and time to execute components or module of software.
Thus, it becomes necessary to evaluate the object(s) standard through statistical method during development and execution of software modules either separately or in an integrated form. Every software system requires test cases and statistical methods to meet the quality standard in software industries. It ensures quality parameters of object to build the strengthen of relationship among different objects under Transaction Management System (TMS) which defines and contained the component status and object(s) accessing status as well under any software development system. It also ensures 
detection of flaw, removal of flow and organizing of object(s) data in the system. Here, methods are used to test object(s) qualities parameter, thus it compared the required quality level of the system which expressed in either acceptable form or improvement form. Utilization of object(s) model under software development system becomes higher after statistical method evaluation process. During statistical test, determination of executable test cases, flaws detection, organizing of object(s) data, interpretation of object data's and presentations of data established perfection in utilization of objects in software development process. It is difficult to measure the reliability of object through statistical model ${ }^{1}$.

This paper is contains sections as follows. In Section II we discuss background of statistical model in software development process. Our discussion includes different statistical model and its impact during evaluation of modules. In Sections III and IV we describe the Statistical model for software reusability and selection of statistical model for software development process and also describe object's qualities evaluation through statistical method and in section $\mathrm{V}$ contains results and conclusions from this article.

\section{Background of statistical model in software development process}

There are various statistical model developed and used in software development process for many application based industries and embedded software as well. Statistical model used to detect error and flaw in the system with transparency of utilizing minimum resources in an application. During functional phase of software, its various qualities considered and developed on statistical (multivariate) model $^{2}$. Sometimes, it found error and flaw information generated during unit testing. These models were originally developed and designed to meet software reliability and reusability of unit and module of software in the proposed system.

Statistical model is beneficial in software development process in code optimization phases. Code optimization helps statistical model in terms of:

- $\quad$ Organizing code in executable module

- $\quad$ Code organization (using macros!)

- $\quad$ Frequent result analysis and assessment.

- $\quad$ Protocol for model updates.

In any statistical model, monitoring is the process of giving efforts to evaluate accuracy in the system. For different development condition, test cases, process of error resolving and development process of software, a statistical model proposed. Models assume the utilization and reliability of a software system to increase the utilization factor of resources and resolve the conflict at some instant. It is unexpected to find an ad hoc improvement of object(s) that works in all system ${ }^{3}$. In statistical utilization model, focus is on increase the growth of utilization and reliability of object(s).

Once an appropriate model is found, the corresponding reliability and utilization curves can be used to extrapolate the object(s) results to the (nearby) future development of software for any application or industry based implementation tool.

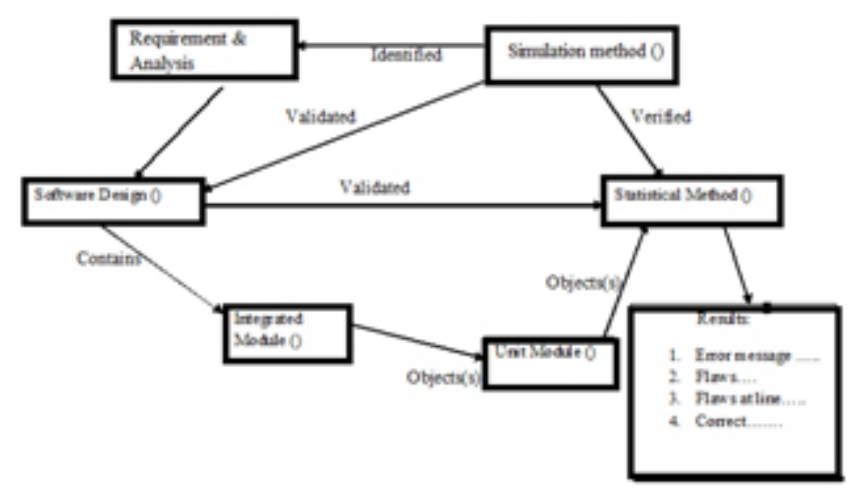

Fig. 1: Status of statistical method 
Thus enabling model or method to predict the growth and progress in reliability of the software system when testing is perform continued and to evaluate the remaining error in the system. While development of new application based software system or any integrated system, several users depend on the system periodically. Every time the system maintain standard of development procedure in industry to provide the right product on right time without any error. Testing come under the process of development and deployment of product.

\section{Evaluation of object qualities performances through Statistical model}

From object qualities performances point of view, evaluation through statistical model requires various data's related to the reusability factor of the development process of software. Software development process works by approaching two things: first is the process and second is qualities evaluation and outcome which include reliability, availability, functionality and life-cycle $\operatorname{cost}^{4}$. It is an important task to define and evaluate various objects' qualities performance to enhance the performance in any application based software. After analyzing all the object qualities aspects in terms of dependent and independent attributes of application software and its various modules, test assumptions require.

$\checkmark$ indicates used in statistical model and $X$ indicates not used in statistical model

For the analysis of repeated object(s) data, most of the currently available object(s) are adequate for normal graphical display, analysis at individual time position or using the available approach $^{5}$. Apart from selection matrix, object qualities model under statistical method generates error at different level which would be suitable under TMS (Transaction Management System) that provides different object's and error generation test cases(given below) which further needs efficiency improvement such as:

Table 1. Object(s) performance related data's in statistical modelSelection matrix

\begin{tabular}{|c|c|c|c|}
\hline SI.No & $\begin{array}{l}\text { Object(s) performance in } \\
\text { statistical model }\end{array}$ & $\begin{array}{l}\text { Used in } \\
\text { Statistical } \\
\text { Model }\end{array}$ & $\begin{array}{l}\text { Reused in } \\
\text { software } \\
\text { development } \\
\text { process }\end{array}$ \\
\hline 1. & $\begin{array}{l}\text { Object's data requirement and } \\
\text { hypothesis in either unit or } \\
\text { module testing }\end{array}$ & $\checkmark$ & $\checkmark$ \\
\hline 2. & $\begin{array}{l}\text { Object's testing data intervals } \\
\text { consist of different length }\end{array}$ & $\checkmark$ & $\checkmark$ \\
\hline 3. & $\begin{array}{l}\text { Detection of flaw or error } \\
\text { which may be dependent or } \\
\text { independent of each other }\end{array}$ & $\checkmark$ & $\checkmark$ \\
\hline 4. & $\begin{array}{l}\text { Object's failure of accessing } \\
\text { task }\end{array}$ & $\checkmark$ & $\checkmark$ \\
\hline 5. & Testing effort rate & $\checkmark$ & $\checkmark$ \\
\hline 6. & $\begin{array}{l}\text { Remaining error or flaw } \\
\text { detection rate }\end{array}$ & $\checkmark$ & $\checkmark$ \\
\hline 7. & $\begin{array}{l}\text { Object's failure need not be } \\
\text { reuse instantly }\end{array}$ & $\checkmark$ & $\checkmark$ \\
\hline 8. & $\begin{array}{l}\text { Imperfect correctness of object } \\
\text { error allowed }\end{array}$ & $\checkmark$ & $x$ \\
\hline 9. & Indefinite amount of data & $X$ & $x$ \\
\hline 10. & Interval count object's data & $\mathrm{X}$ & $\checkmark$ \\
\hline
\end{tabular}


Selection of statistical Model for software development process

If the objects are highly available and have constant error rate, the Poisson distribution will produce right level of approximation for any developing system ${ }^{6}$. But, out of $n$ statistical based model, NOT all are important to go through software development process. Selection of statistical method based on the reliability and growth rate of reusability factor. The outcome depends on the active data set provided in the system which directly or indirectly related to performance of objects. This results into appropriate plots or more formally with trend tests in development process. The purposes of statistical model in software development process are prediction, mining of information and report of stochastic structures because of its nondeterministic in nature.

It is always favorable to use the below approaches in order to use statistical model and develop the ability to make an appropriate option:

i. Procedural and algorithmic approach, having an effect on objective and learning process of software development.

ii. Systematically approach, which affects both objects and the process of implementation.

iii. Activities \& requirement approach influencing the process aspect of learning.

Table 2. Generation of object error during softawre development process

\begin{tabular}{llcc}
\hline Category & $\begin{array}{l}\text { Source } \\
\text { description }\end{array}$ & $\begin{array}{c}\text { \#Error generated } \\
\text { (Absolute/Relatively) }\end{array}$ & $\begin{array}{c}\text { Efficiency improvement } \\
\text { required during Software } \\
\text { development process (SDP) }\end{array}$ \\
\hline
\end{tabular}

\begin{tabular}{llcl}
1 & Error in new object & $\checkmark$ & Yes \\
2 & Design error & $\checkmark$ & Yes \\
3 & Testing platform error & $\checkmark$ & Yes \\
4 & Integrating objects error & $\checkmark$ & Yes \\
5 & Existing object in existing software & $\checkmark$ & Yes \\
6 & Erroneously maintain as error/defect & $\checkmark$ & Yes \\
7 & Unknown object & $X$ & Yes \\
8 & Undefined object & $X$ & Yes \\
9 & Category undefined objects & $X$ & Yes \\
10 & Metric(s) measurement error & $X$ & Yes \\
\hline
\end{tabular}

Table 3. A RELATIONSHIP OF OBJECT QUALITIES

\begin{tabular}{lcccccc}
\hline $\begin{array}{l}\text { Objects set } \\
\text { (unit of hr) }\end{array}$ & $\begin{array}{c}\text { Object } \\
\text { (X) }\end{array}$ & $\begin{array}{c}\text { Efficiency } \\
\text { (Y1) }\end{array}$ & $\begin{array}{c}\text { Reliability } \\
\text { (Y2) }\end{array}$ & $\begin{array}{c}\text { Portability } \\
\text { (Y3) }\end{array}$ & $\begin{array}{c}\text { Usability } \\
\text { (Y4) }\end{array}$ & $\begin{array}{c}\text { Functionality } \\
\text { (Y5) }\end{array}$ \\
\hline 1. & X1 & 1 & 1 & 0 & 1 & 1 \\
2. & X2 & 1 & 0 & 1 & 0 & 1 \\
3. & X3 & 1 & 1 & 1 & 1 & 0 \\
4. & X4 & 1 & 0 & 1 & 1 & 1 \\
5. & X5 & 1 & 1 & 0 & 0 & 1 \\
6. & X6 & 1 & 0 & 0 & 1 & 1 \\
7. & X7 & 0 & 1 & 1 & 1 & 1 \\
8. & X8 & 1 & 0 & 1 & 1 & 1 \\
9. & X9 & 1 & 1 & 0 & 1 & 1 \\
10. & X10 & 0 & 1 & 1 & 1 & 0 \\
\hline
\end{tabular}


iv. Metric(s)-oriented approach affects the reusability process, primarily carrying out different characteristics and its statistical qualities.

Performance is a parametric concern of software process quality which often not consider at initial stages of software development process. These statistical model analyses are applicable to the system where many object being used under any development process of software. It provides an approach to use objects in a standard and procedural manner for which an algorithm can be designed. Various methods and model applicable to identify collection, verifying, organizing and presentation of object(s) data in the development process

statistical model for identifying qualities in software development:

Software error and flaws are not only an individual component of software product development process but also an important factor of software Quality as well. It is not possible to completely eliminate software defects or flaws at one go. Developers avoid or minimize error or flaws in software development process much as possible. To deliver error free software is a challenging task and it is imperative to predict, calculate and analyze statistically the defects before delivery of software product.

Different object set and their qualities used in a developing system where sometime it is required or not required, object set, $X=\{X 1, X 2, X 3, X 4, X 5, X 6, X 7, X 8, X 9, X 10\}$
Where,

1- Stands for reusable in software development process and

0- Stands for "Not required" and Time measured in unit of hours.

This model identified and implement through linear regression also, which consist of constant object " $X$ " and its dependent qualities such as Efficiency, Reliability, Portability, Usability, and Functionality that defined such as:

I. $Y=a+b X$

II. $Y=(X 1 Y 1+X 2 Y 2+X 3 Y 3+$ $+\mathrm{XnYn})$

\section{Object utilization through Statistics Models}

The ideas behind this object utilization through statistics models are to show the fulfillment of object and the response under which a decision can be taken for object utilization facts and improvement as well in software development process. This task can be achieved by using descriptive statistics also which uses tabular, graphical pictorial and numerical methods of representations by which essential qualities of a

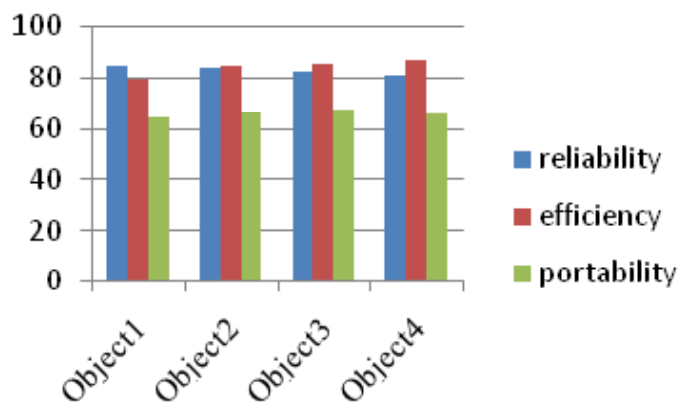

Fig. 2: Responses during software development process

Table 4. Frequency distribution of object utilization

\begin{tabular}{ccccc}
\hline Object set & $\begin{array}{c}\text { Fulfillment } \\
\text { status } \\
\text { (range*) }\end{array}$ & \multicolumn{3}{c}{$\begin{array}{c}\text { Responses during software } \\
\text { development process }\end{array}$} \\
\hline Object 1 & $65-85$ & 85 & Efficiency & $\begin{array}{c}\text { Portability } \\
\text { (\%) }\end{array}$ \\
Object 2 & $65-85$ & 84 & 80 & 65 \\
Object 3 & $65-85$ & 83 & 85 & 67 \\
Object 4 & $65-85$ & 81 & 86 & 68 \\
\hline
\end{tabular}


sample object can be designed and evaluated. A demonstration can be understood as an example given below.

*indicates different object set provides a same range of qualities, where object set can be accessible in different component or module in development process.

When object's qualities observed, quantitative data arrived which can be defined through percentage or number whereas continuous object may assume any value or data, apart from any other precision constraint of object imposed by the other developed system.

\section{CONCLUSION}

In order to improve quality of software development, we can make use of statistical model for evaluation of object utilization at various levels.
We identified the statistical model for evaluation process and also evaluated object's qualities. Different set of object's performance measured in development as well as reuse cases also. TMS used to differentiate sources of description of objects based on parameter which are important to evaluate error in the object set and efficiency improvement factor for objects in software development process. Statistical model used to show the relationship between qualities of objects at various levels which generated in equation form. This paper shows how object utilization factor improved through statistical model and presented.

However, more descriptive and predictive statistical model required for object(s) at execution level for testing of module and integrates it into component format for successful implementation and also to provide high impact on removal efficiency of flaw of system(s).

\section{REFERENCES}

1. Goel, A. L. (1985). Software reliability models: assumptions, limitations, and applicability. IEEE Trans. Software Eng., 11(12):14111423.

2. Joe, H. (1989). Statistical inference for General-Order-Statistics and Non homogeneous-Poisson-Process software reliability models. IEEE Trans. Software Eng., 15(11):1485-1490.

3. Joe, H., Reid, N. (1985). Estimating the number of faults in a system. J. Amer. Stat. Assoc., 80(389):222-226.

4. Musa, J. D. (2006). Software Reliability Engineering: More Reliable Software Faster and Cheaper, 2nd ed. Bloomington: Author House.

5. Rigdon, S. E., Basu, A. P. (2000). Statistical Methods for the Reliability of Repairable Systems. New York: Wiley.

6. Singpurwalla, N. D., Wilson, S. P. (1994). Software reliability modeling. International
Statistical Review, 62: 289-317.

7. Xie, M., Hu, Q. P., Wu, Y. P., Ng, S. H. (2007). A Study of the Modeling and Analysis of Software Fault-detection and Faultcorrection Processes, Qual. Reliab. Engng. Int., 23(4):459-470.

8. Zhang, X., Jeske, D. R., Pham, H. (2002). Calibrating software reliability models when the test environment does not match the user environment. Appl. Stoch. Models Bus. Ind. 18: 87-99.

9. S. Counsell, G. Loizou, and R. Naijar, "Quality of manual data collection in Java software: an empirical investigation," Empirical Software Engineering, 12, pp. 275-293, 2007.

10. Serban, C., Vescan, A., Pop, H. F., A Formal Model for Component-Based System Assessment, Second international conference on Computational Intelligence, Modelling and Simulation, pp. 261-266, 2010. 